\title{
X- Ray generation via Thomson Scattering
}

\author{
Salim H. Al-Shamma \& Muzahim I. Azawe \\ \& \\ Lubna H. Ismail \\ Department of Physics / College of Education \\ Mosul University
}

Received
$03 / 01 / 2010$

Accepted

27 / 06 / 2010

\section{الخلاصة: - مان}

$$
\begin{aligned}
& \text { تم في هذا البحث بناء برنامج محاكاة نظرية لاستطارة ثومسون بين حزمة الليزر وحزمة } \\
& \text { الالكترونات ذات طاقة نسبية عالية ـتم من خلال هذه الدراسة حساب عدد فونونات الأشعة } \\
& \text { السينية المنبعثة لكل زاوية مجسمة ولمختلف زوايا الانبعاث عند زاوية استطارة معينة تساوي }
\end{aligned}
$$

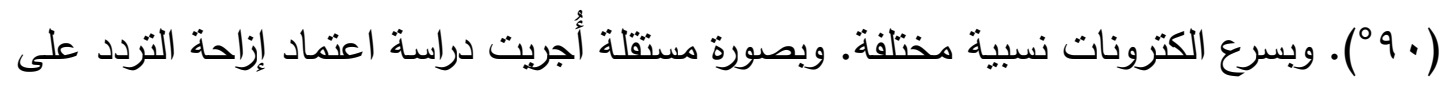

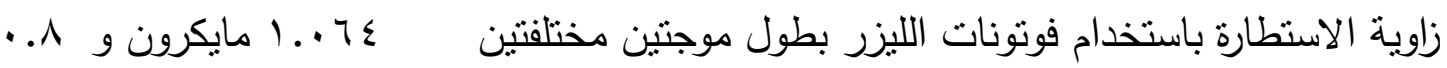

$$
\begin{aligned}
& \text { مايكرون • إضافة إلى ذلك أُجريت دراسة على اعتماد ذروة إزاحة التردد مع طاقات الالكترون }
\end{aligned}
$$

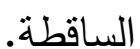

\begin{abstract}
:
In this paper, a theoretical simulations had been made via Thomson scattering to determine the number of photons of x-ray emitted per solid angle for a wide range of angles of observation of $\mathrm{x}$-ray. This study had been carried out at fixed scattering angle equal $\left(90^{\circ}\right)$ and different relativistic electron velocities. Also, an independent study had been performed to determine the frequency shift for different scattering angles and using two laser photons wave lengths $(1.064 \mu \mathrm{m}$ and $0.8 \mu \mathrm{m})$. Furthermore, another simulation had been carried out to determine the dependence of peak frequency shift on incident electron beam energies.
\end{abstract}

\section{Introduction:}

A short pulse $\mathrm{x}$-ray source was developed by Thomson scattering (inverse compton) via the interaction between relativistic electron beam and laser light. The mechanism of explaining such process that the 
electric and magnetic components of incident wave accelerate the particle. As it accelerates, it in turn emits radiation in the x-ray region [1]. A short pulse $\mathrm{x}$-ray source is considered an important probes for study the dynamics of the material and structure of solid, industrial applications and medical imaging applications compared to other light sources such as Ti:s laser of wavelength $(800 \mathrm{~nm})$ [2,3]. The $\mathrm{x}$-ray generation of Thomson scattering has many important advantages such as a good directional radiation, high brightness, tunable wavelength and the intensity of x-ray is proportional to densities of both electron and laser beams [4].

$\mathrm{X}$-ray sources had been the subject of different researches groups[5-10]. In this work, a computer program was built for Thomson scattering simulation to determine the number of $\mathrm{x}$-ray photons emitted per solid angle over different angles of observations. Knowing that this study had been carried out at a fixed scattering angles equal $\left(90^{\circ}\right)$ and for different electron velocities. In addition, a study was made to determine the frequency shift for different scattering angles.

\section{Theory}

A schematic configuration of thomson scattering is shown in fig (1).

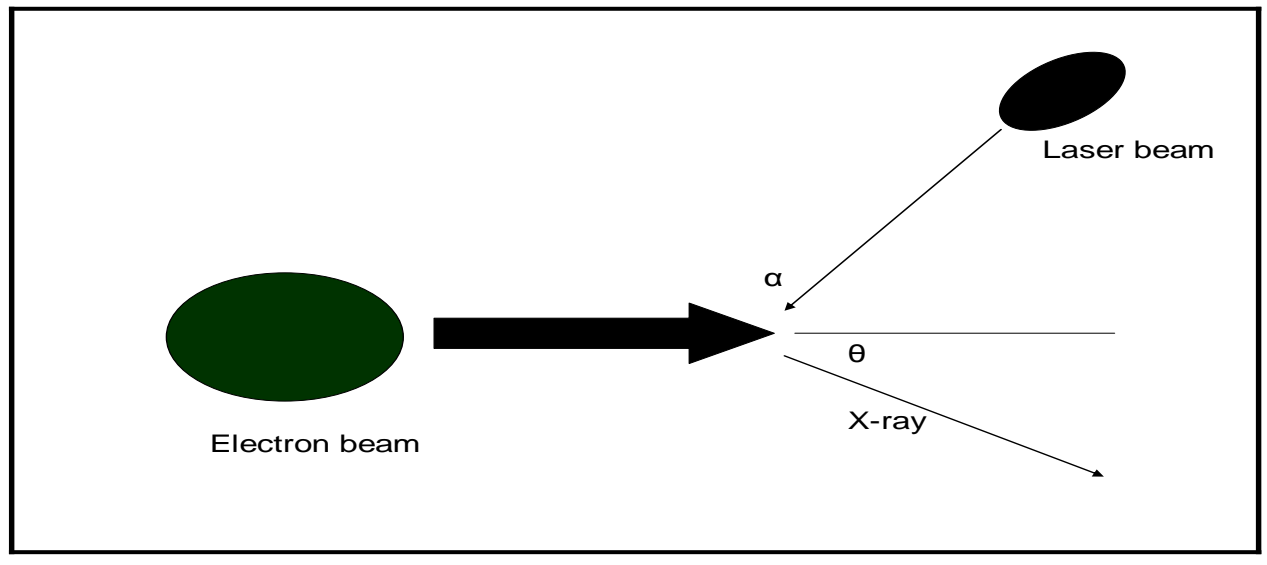

Fig(1)Diagram of interaction configuration

The generation of $\mathrm{x}$-ray as matter of fact is the inverse Compton scatter effect where as a beam of accelerated electrons is collided with the laser light beam. The number of $\mathrm{x}$-ray photon in the produced $\mathrm{x}$-ray is given by[8].

$\frac{d n_{x}}{d \Omega}=C_{o f f} \frac{n_{e} n_{i}}{\sqrt{2 \pi}} \frac{d \Sigma}{d \Omega} \frac{1}{\sqrt{\left(\delta_{e y}^{2}+\delta_{l y}^{2}\right)\left[(1-\cos \alpha)\left(\delta_{e x}^{2}+\delta_{l x}^{2}\right)+(1+\cos \alpha)\left(\delta_{e z}^{2}+\delta_{l z}^{2}\right)\right.}}---(1)$

Where

$\delta_{\mathrm{ex}}, \delta_{\mathrm{ey}}, \delta_{\mathrm{ez}}$ are the electron beam rms sizes

$\delta_{\mathrm{ex}}, \delta_{\mathrm{ey}}, \delta_{\mathrm{ez}}$ are the laser beam rms sizes

$\alpha$ is the Thomson scattering angle.

$\mathrm{n}_{\mathrm{e}}$ is the number of electrons per pulse. 
$\mathrm{n}_{1}$ is the number of photons per pulse.

$\frac{d \Sigma}{d \Omega}$ is the Thomson cross section and is given by

$\frac{d \Sigma}{d \Omega}=\frac{r_{o}^{2}\left(1+\beta^{2}\right)\left(1+\cos ^{2} \theta\right)-4 \beta \cos \theta}{2 r^{2}(1-\beta \cos \theta)^{4}}---(2)$

Where

$\theta$ is the angle of $x$-ray observation.

$r_{0}$ is the classical radius of electron.

$\beta$ is the velocity of electron with respect to velocity of light(v/c).

$\mathrm{c}_{\text {off }}$ is a coefficient which shows the mismatch of position and time of electron and laser beams.

And is given by

$c_{o f f}=\exp \left[-\frac{\left(y_{e o}-y_{l o}^{\prime}\right)^{2}}{2\left(\delta_{e y}^{2}+\delta_{l y}^{2}\right)}-\frac{\left[\left(z_{e o}-z_{l o}^{\prime}\right) \cos (\alpha / 2)-\left(x_{e o}-x_{l o}^{\prime}\right) \sin (\alpha / 2)\right]^{2}}{(1-\cos \alpha)\left(\delta_{e x}^{2}+\delta_{l x}^{2}\right)+(1+\cos \alpha)\left(\delta_{e z}^{2}+\delta_{l z}^{2}\right)}\right]--(3)$

Where $\left(\mathrm{y}_{\mathrm{eo}}-\mathrm{y}_{10}\right)$ and $\left(\mathrm{x}_{\mathrm{en}}-\mathrm{x}_{10}\right)$ represent the transverse differences between electron and laser beams spatial position.

$\left(\mathrm{Z}_{\mathrm{eo}}-\mathrm{Z}_{\mathrm{lo}}\right)$ represent the longitudinal differences between electron and laser beams. When a laser beam interacts with an electron beam at an angle aplha experience a Doppler shift with the peak frequency given by[9].

$$
w=\frac{2 \gamma^{2}(1-\cos \alpha)}{1+a_{o}^{2} / 2} w_{o}--(4)
$$

Where $\gamma=\mathrm{E} / \mathrm{E}$, $\mathrm{E}$ is the relativistic electron energy and $\mathrm{E}_{\mathrm{o}}$ is its rest energy

$\mathrm{a}_{\mathrm{o}}$ :laser strength parameter which is equal.

$a_{o}=\frac{v}{c}=0.85 * 10^{-9} * I^{1 / 2}\left[\frac{w}{\mathrm{~cm}^{2}}\right] * \lambda_{o}[\mu m]$

where $\lambda_{\mathrm{o}}$ is the laser wave length.

$v$ is the electron velocity in the laser field.

\section{Results and Discussions:}

The results below, a theoretical simulation had been obtained via Thomson scattering, where an electron of relativistic energy is collided with a laser light. The dependence of the coefficient (coff) eq (3) on the scattering angle (alpha) for different value of transverse and longitudinal differences between the electron and laser beams where $\left(\mathrm{dx}=\mathrm{X}_{\mathrm{eo}}-\mathrm{X}_{\mathrm{io}}\right.$, $\mathrm{dy}=\mathrm{y}_{\mathrm{eo}}-\mathrm{y}_{\mathrm{io}}$, and $\mathrm{dz}=\left(\mathrm{z}_{\mathrm{e} o}+\mathrm{z}_{\mathrm{io}}\right)$ have been plotted. The maximum value of coff equal to 1 , for the values of $(\mathrm{dx}=\mathrm{o}, \mathrm{dy}=\mathrm{o}$ and $\mathrm{dz}=0)$ as shown in fig. (2)while for chosen values $(\mathrm{dx}=0.5 \mathrm{~mm}, \mathrm{dy}=0.5 \mathrm{~mm}$ and $\mathrm{dz}=0$, ), the coefficient was $(0.5)$ at zero scattering angle $(\alpha)$ and shows a little bit 
increase at $\propto=180^{\circ}$. Also, shown in the same graph for the value $(\mathrm{dx}=0$, $\mathrm{dy}=0.5 \mathrm{~mm}$ and $\mathrm{dz}=0$ ), the coefficient is 0.55 at zero scattering angle and shows a dip at $\propto=180^{\circ}$. This behavior is in contrast to the previous value. Fig (3) shows the behavior of the coefficient with respect to the angle $(\alpha)$ but for keeping one of the parameters ( $\mathrm{dx}$, dy and $\mathrm{dz}$ ) equal to zero. One can notice that when the angle $(\alpha)=0$ an increase in the coefficient was occurred.

Coefficient has shown a large decrease in its value when the angle $(\alpha)$ was $180^{\circ}$. When $(\mathrm{dx}=0.6 \mathrm{~mm}, \mathrm{dy}=0.2 \mathrm{~mm}$ and $\mathrm{dz}=0.2 \mathrm{~mm})$ with respect to $(\mathrm{dx}=0.2 \mathrm{~mm}, \mathrm{dy}=0.2 \mathrm{~mm}$ and $\mathrm{dz}=0.2 \mathrm{~mm})$ and $(\mathrm{dx}=0.2 \mathrm{~mm}$, $\mathrm{dy}=0.2 \mathrm{~mm}$ and $\mathrm{dz}=0.2 \mathrm{~mm}$ ) has shown in fig. (4).

Fig. (5) shows that a similar behavior as in fig. (4) but with $(\mathrm{dx}=0.2 \mathrm{~mm}$, ady $=0.1 \mathrm{~mm}$ and $\mathrm{dz}=0.2 \mathrm{~mm})$ and $(\mathrm{dx}=0.6 \mathrm{~mm}, \mathrm{dy}=0.2 \mathrm{~mm}$ and $\mathrm{dz}=0$ ). fig. (6) shows a peculiar behavior when the parameters $(\mathrm{dx}, \mathrm{dy}$ and $\mathrm{dz}$ ) was kept to zero value and the other equal to 0.1 , otherwise, when $\mathrm{dx}=\mathrm{o}$, there was an increase in coefficient value with respect to $\alpha$. The dependence of the number of $\mathrm{x}$-ray photons on scattering angle $(a l p h a=90)$ for different-electron impact velocities. Fig. (7) shows the classical behavior of the number of $\mathrm{x}$-ray photons per solid angle for different classical velocities of electron $(0.05 \mathrm{c}$ and $0.07 \mathrm{c})$. One can see from this figure, the periodicity behavior of Thomson differential cross section due to the influence of $\cos ^{2} \theta$. Fig. (8) shows the dependence of the number of photons per solid angle on the angle (theta) for the electron velocities $(0.1 \mathrm{c}, 0.3 \mathrm{c}$ and $0.5 \mathrm{c})$. this figure shows a decrease of the number of photons par solid angle with the increasing of the angle (theta). Fig. (9 and 10) show a shape decrease of the number of photons per solid angle which is quite different from the last figures. This is due to high relativistic electron velocity. So in this case, the number of photons per solid angle is independent on the angle (thela).

The dependence of frequency shift on the scattering angle (eq.4) had been obtained as shown in figures (11 and 12). These simulations had been carried out at two laser wavelengths $(1.064 \mu \mathrm{m}$ and $0.8 \mu \mathrm{m})$ and four relativistic electron energies (20Mev, $40 \mathrm{Mev}, 60 \mathrm{Mev}$ and $80 \mathrm{Mev}$ ). One can notice from these figures that there was a clear peak shift frequency for different relativistic electron energies. Furthermore, no shifts in the position of the central peaks.

Fig. (13) shows the peak frequency shift a function of electron beam energies for two laser wavelengths $(1.064 \mu \mathrm{m}$ and $0.8 \mu \mathrm{m})$. One can see that from the figure that the peak frequency shift increases with increase of the electron energies. 
Salim H. Al-Shamma \& Muzahim I. Azawe \& Lubna H. Ismail

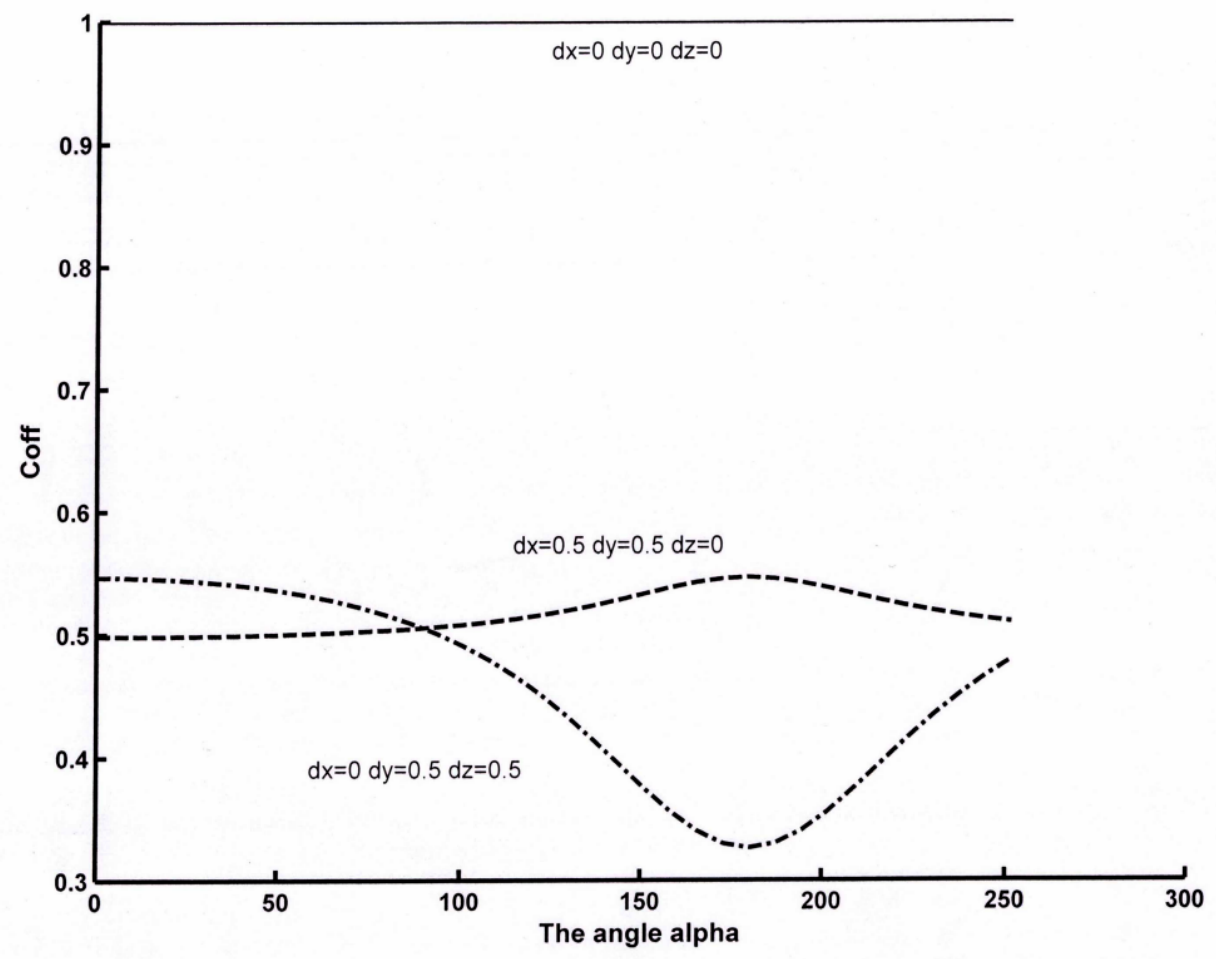

Fig (2) Coff as a function of the angle alpha

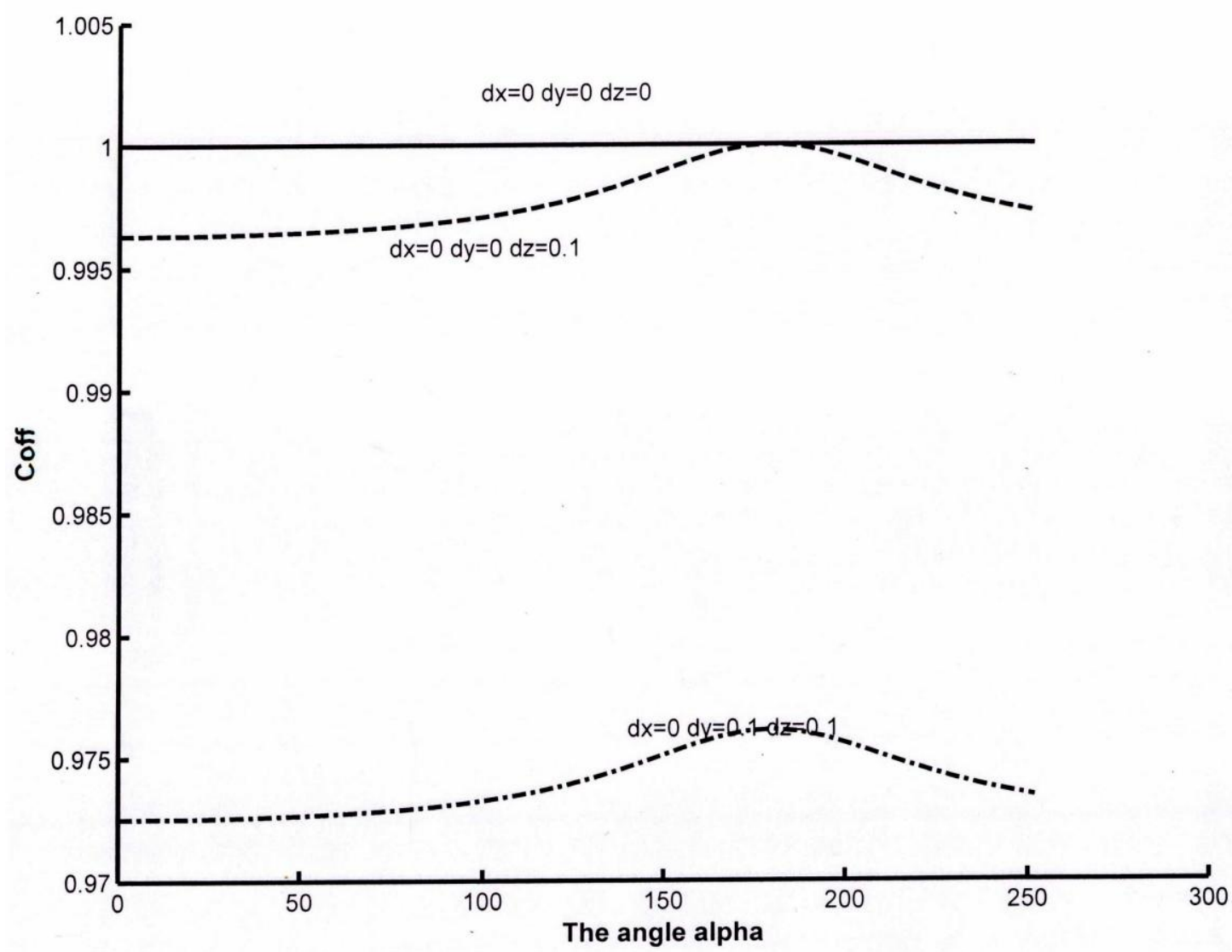

Fig ( 3 ) coff as a function of the angle alpha 


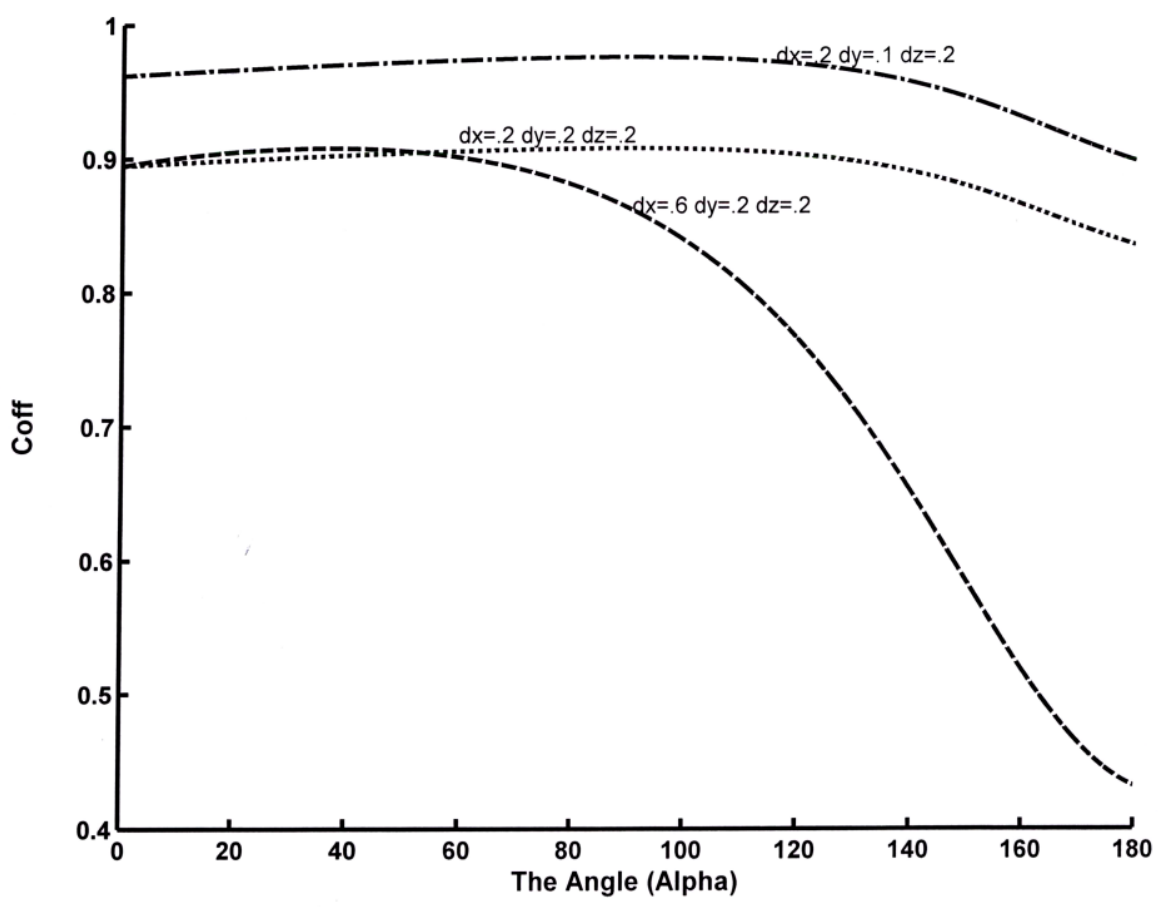

Fig.( 4 ):Coff as a function of the angle aplha

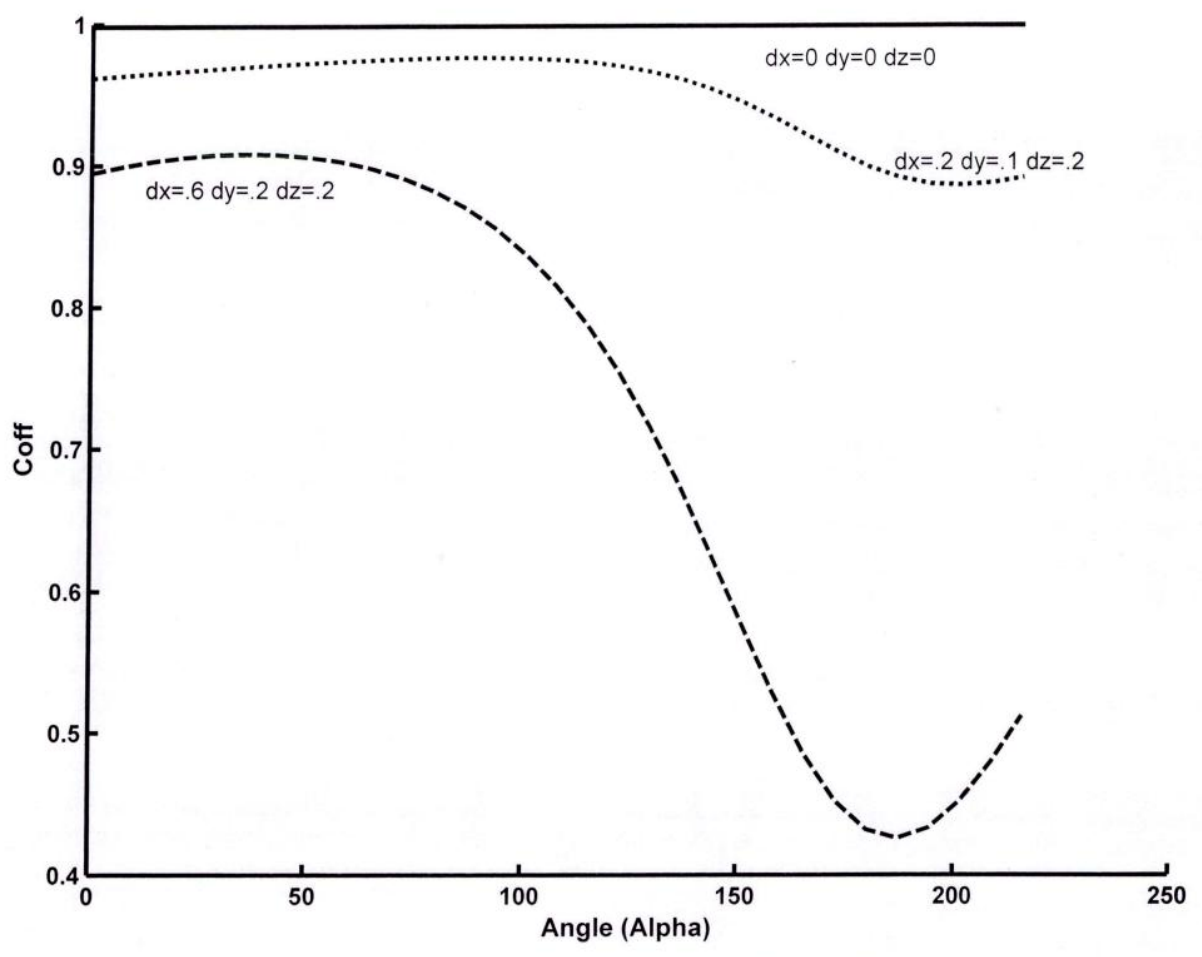

Fig. ( 5 ):Coff as a function of angle Alpha 
Salim H. Al-Shamma \& Muzahim I. Azawe \& Lubna H. Ismail

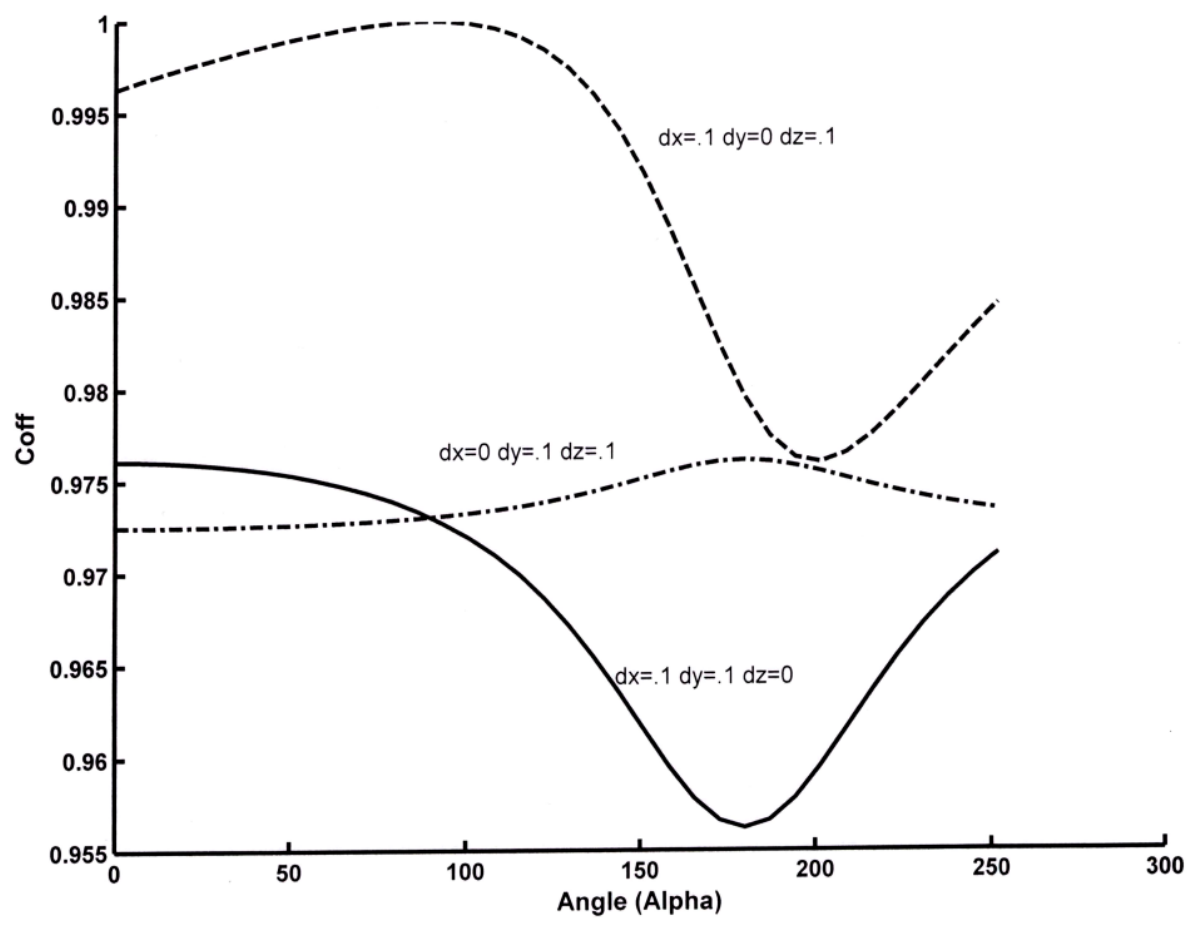

Fig. ( 6 ):Coff as a function of alpha

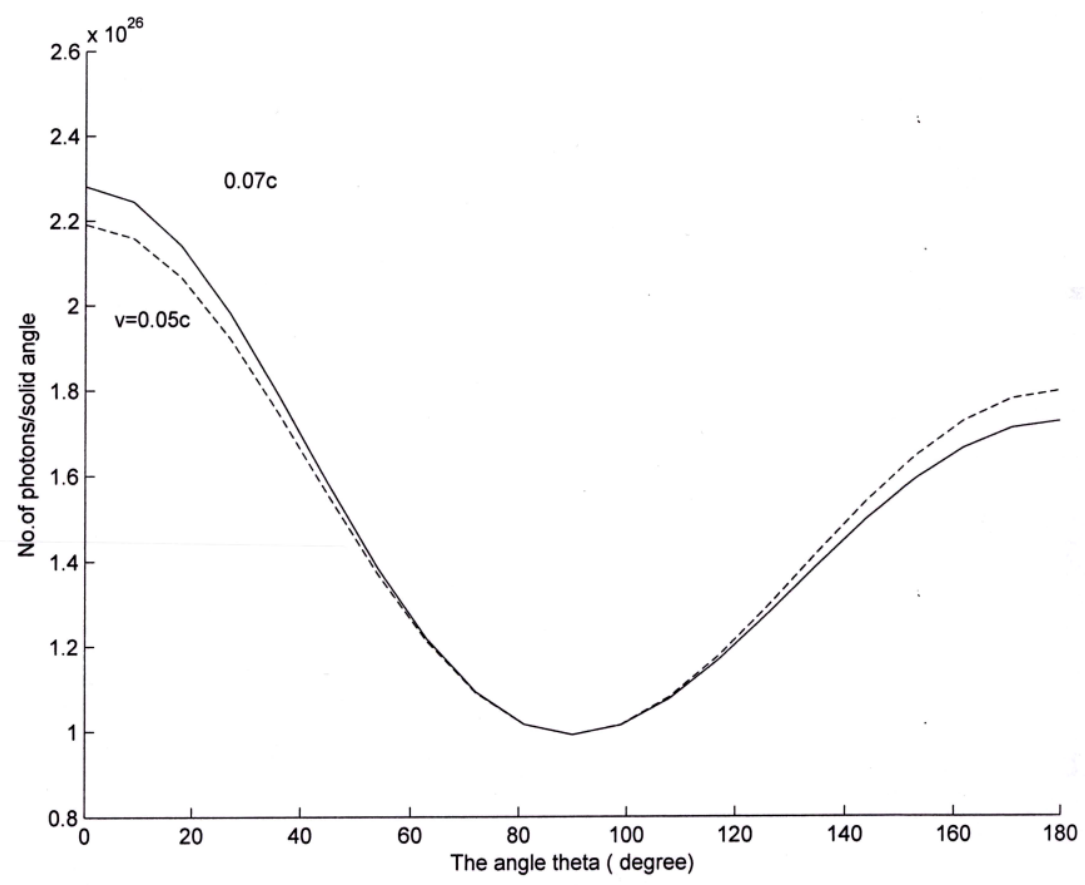

Fig ( 7 ) No.of photons/solid angle against the angle theta ( alpha=90) 


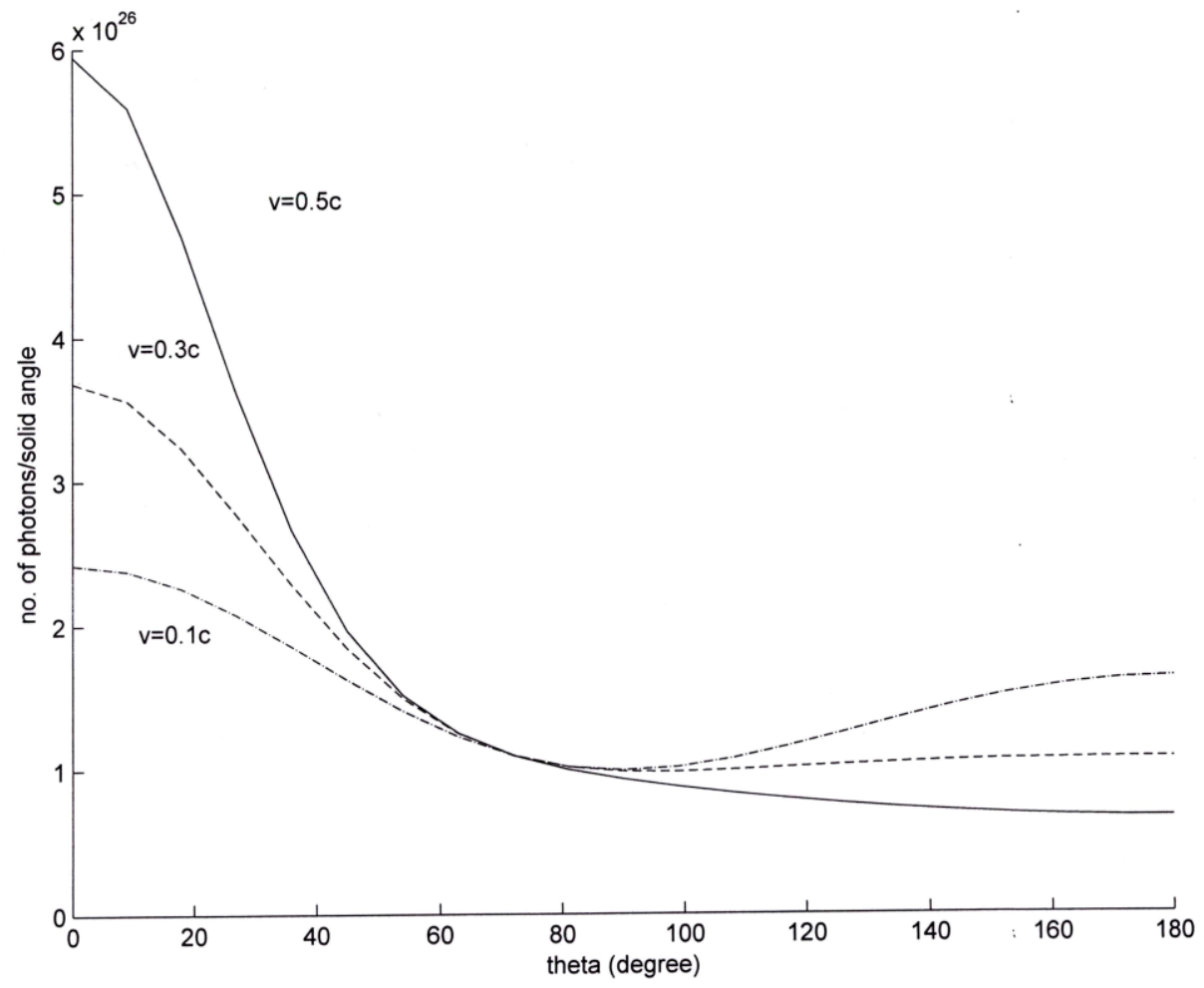

Fig ( 8) No.of photonsper solid angle against the angle theta ( alpha=90)

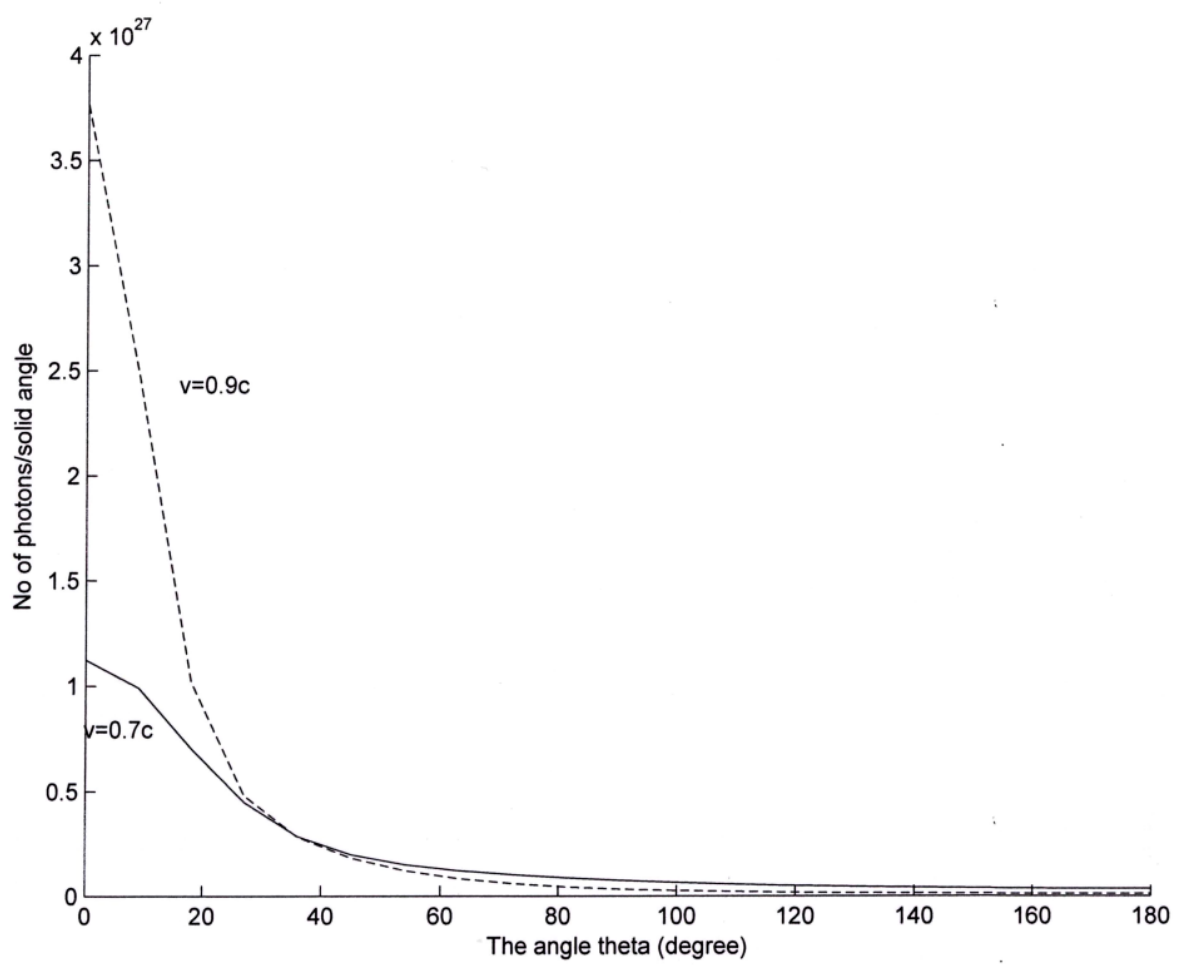

Fig (9)No of photons/solid angle against the angle theta (alpha=90) 


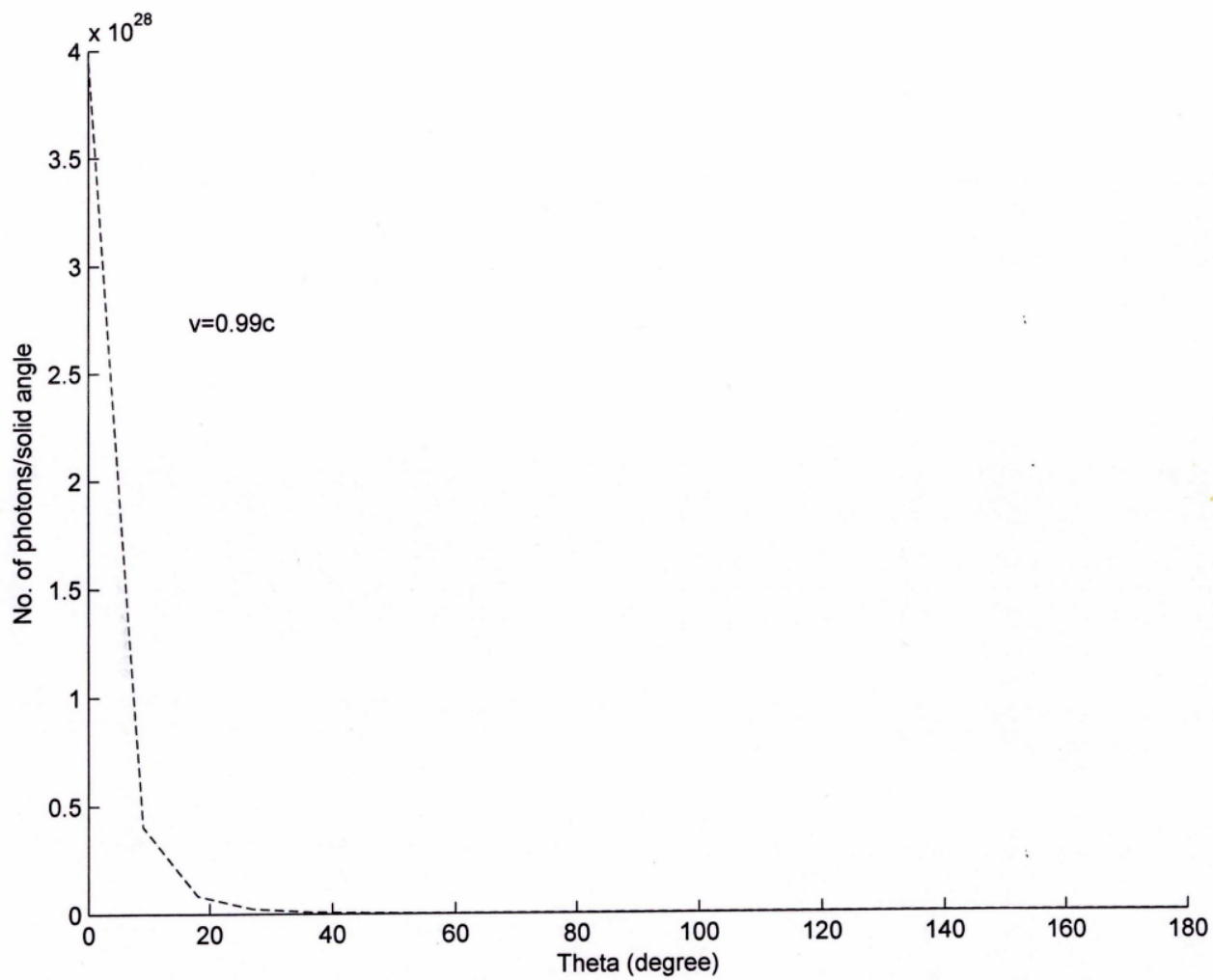

Fig (10) No. of photons/solid angle against the angle theta (alpha=90)

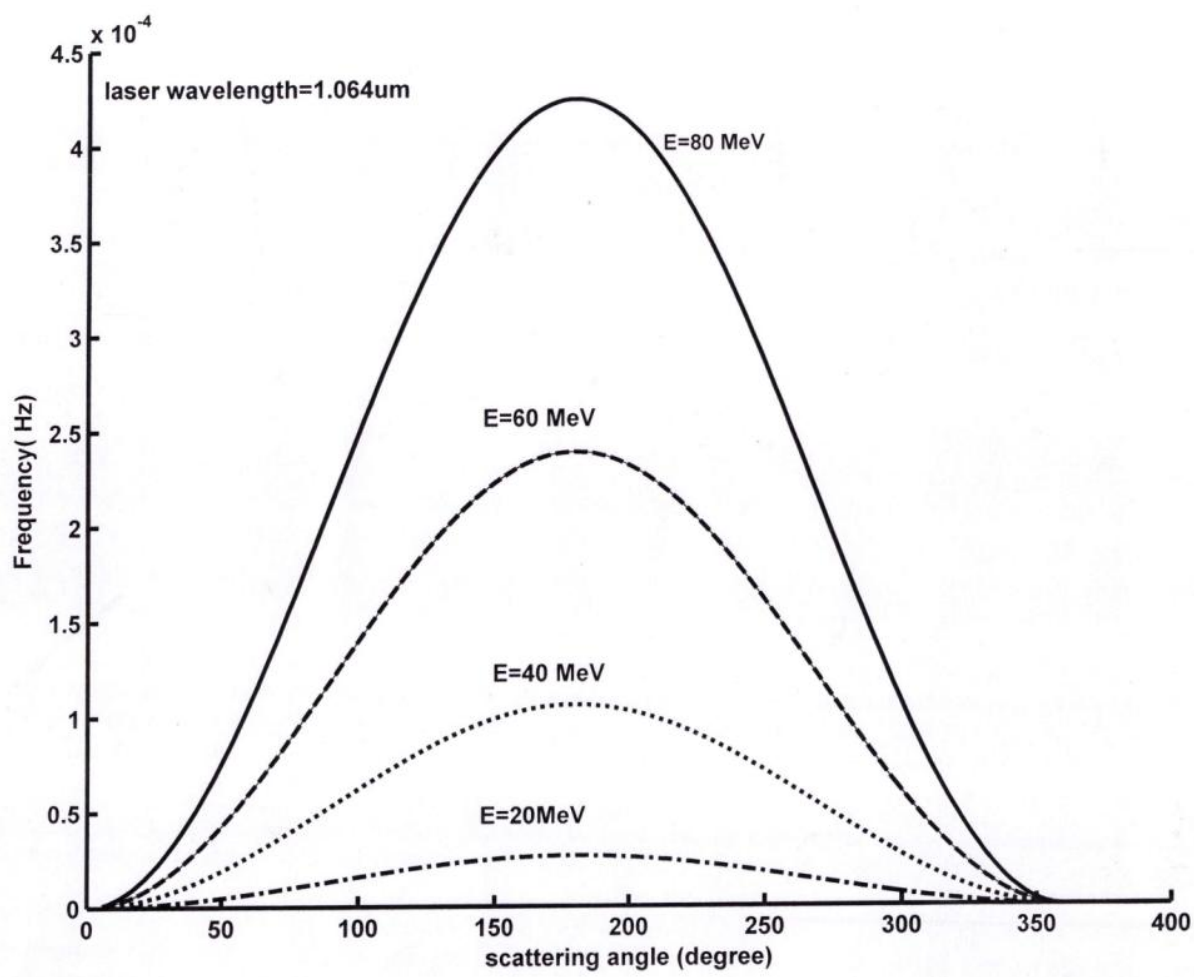

Fig (11) Frequency shift against the scattering angle 


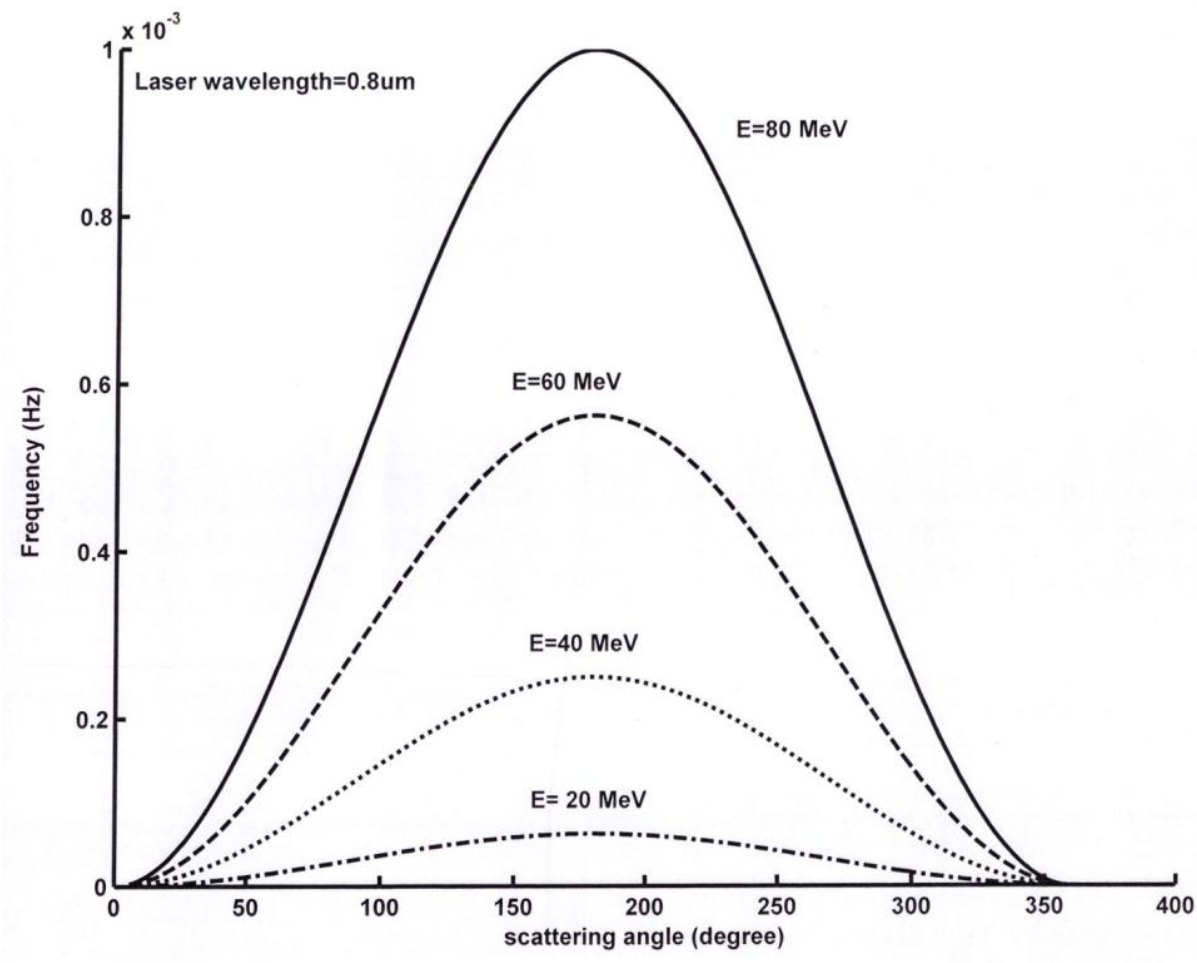

Fig (12) freguency shift against the scattering angle

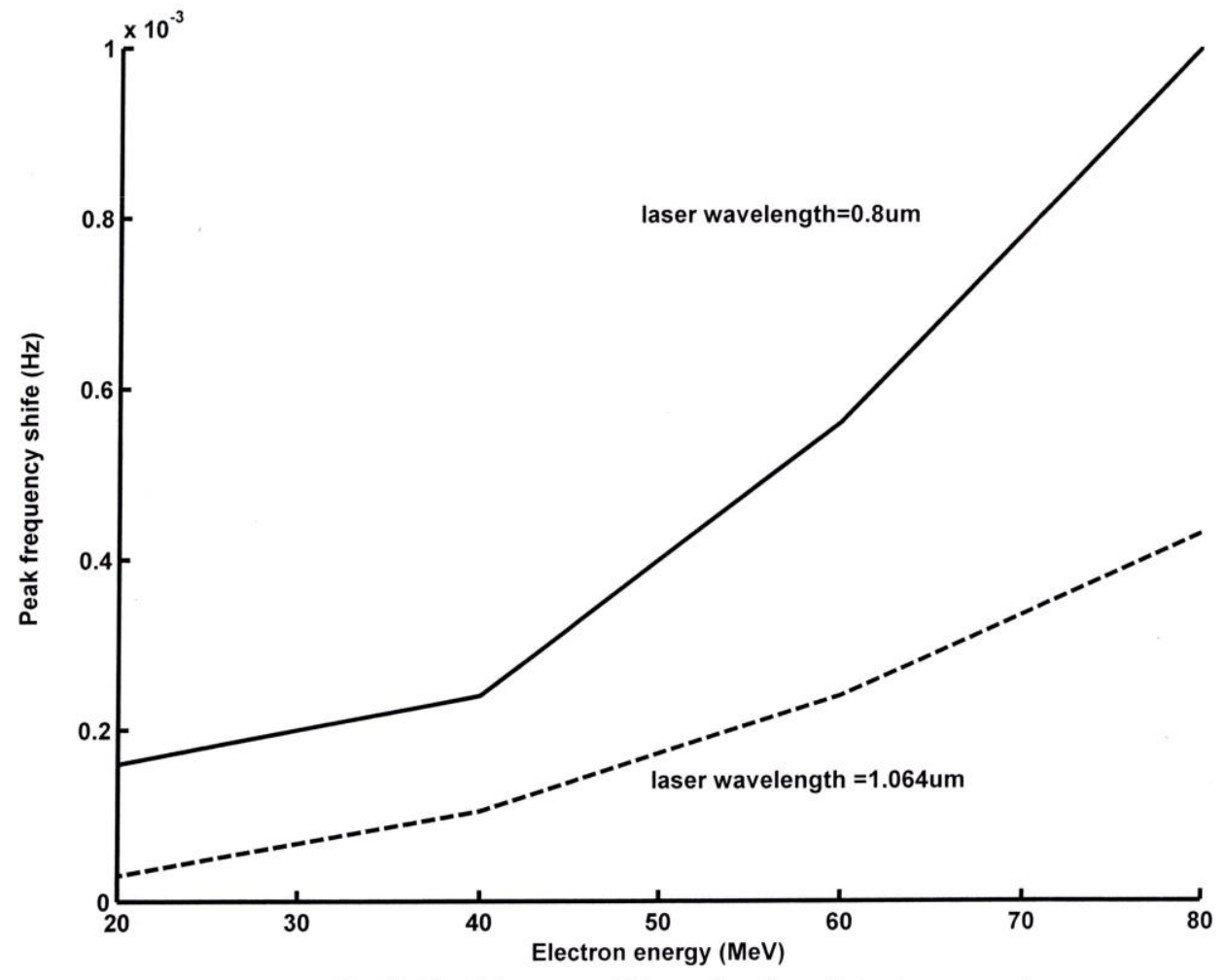

Fig (13) Peak frquency shift as a function of electron energy) 


\section{Conclusions:}

A theoretical simulation has been presented through Thomson scattering between a relativistic electron beam and laser light to estimate some important parameters such as the number of $\mathrm{x}$-ray photons per solid angle (differential cross section) over a wide of $\mathrm{x}$-ray emitting angles starting from low electron energy up 0.99c. furthermore, frequency shift has been simulated over a wide range of scattering angles and energies using two laser wavelengths $(1.064 \mu \mathrm{m}$ and $0.8 \mu \mathrm{m})$.

\section{References:}

1) http://en-wikipedia. Org/wiki/Thomson scattering.

2) A. Zelinsky, E. Bulyak, P. Gladkikh, I. Karnaukhov, A. Mytsykov, A. Shcherbakov. proceedings of EPAC 2004, Lucerne,Switzerland.

3) http://pbpl-physics.Ucla.edu/education/courses/physics-1991/inversecompton.

4) F. Sakai, J. Yang, M. Yorozu, Y. Okada, T. Yanagida. proceedings of the 2001 particle accelerator conference, Chicago.

5) J. Yang, M. Yorozu, F. Sakai, T. Yangida, Y. Okaada, T. proceedings of EPAC 2002, Paris, France.

6) R. Kuroda, D. Ueyama, T. Saito, S. Minaamiguchi, K. Hidume, M. Washio, proceedings of the 2004 FEL conference, Trieste, Italy, 466.

7) www.sung sb-edu/icfa 2001/ papers/w2-5. pdf.

8) CH. X. Tang W. H. Huang, H. B. Chen, C. Cheng, Y. Cheng, Q. Du, T. B. Du, YCH.Du, X. ZHe, J. F. Hua, G. Huang, Y. CH. Ge, Y. zH. Lin, B. Xia, M. Jxu, X. D. Yuan, SH. X. Zheng. proceedings of the 2004 FEL conference, Trieste, Italy, 622.

9) K. Nakajima, H. Nakanishi, A. Ogata, H. Kotaki, H. Ahn, H. Dewa, M. Kando, S. Kondoh, F. Sakai, Particle accelerator, conference May1977, Vancouver, Bc. S .

10) A. Tsunemi, H. Nakanishi, A. Ogata, H. Kotaki, H. Ahn, H. Dewa, M. Kando, S. Kondoh, F. Sakai, particle accelerator conference, May, 1997, Vancouver, BC.

11) G. Priebe, D. Laundy, M. AMacdonald, G. P. Diakun, S. P. Jamison, P. J. Phillips, B. Sheehy, L. B. Jones, D. J. Holder, S. L. Smith, G. J. Hirst, N. Naumova, G. A. Krafft, K. Spohr, H. Legall, J. B. Rosenzweig, F. Gruner, C. P. J. Barty, C. Sidera, U. Schramm, S. Chattopadhyay and E. A. Seddon. Laser and Particle Beam (2008), 26, 619-660 printed in the USA, Cambridge University Press. 